\title{
ADVANCED STRUCTURAL TESTING METHODS FOR SMALL WIND TURBINES BLADE UP TO FAILURE
}

\author{
Dr Časlav Mitrović* \\ Faculty of Mechanical Engineering, Belgrade, Serbia \\ Dr Goran Vorotović, \\ Faculty of Mechanical Engineering, Belgrade, Serbia \\ Dr Nebojša Petrović, \\ Faculty of Mechanical Engineering, Belgrade, Serbia \\ Dragan Stamenković, \\ Faculty of Mechanical Engineering, Belgrade, Serbia \\ Svetlana Stojiljković \\ Aviation academy, Belgrade, Serbia
}

This work demonstrates static testing of a composite blade W55RBVS structure for the wind turbines of up to $6 \mathrm{~kW}$ power. The testing consists of the static testing of the structure up to the moment of the blade failure. The main purpose of the testing is to define and directly verify the rigidity of the blade W55RBVS, to determine the maximum force which leads to faliure and the relative span of the blade failure. W55RBVS composite blades, manufactured by the company WING.doo and are installed on a two-blades wind turbine Eoltec Scirocco. This test is defined in the standard IEC 61400-2 /8/. Blade testing is performed in the Aerotechnics Laboratory of the Faculty of Mechanical Engineering, Belgrade University. The load test is performed up to the moment of the blade failure. The result of the testing will be used in order to improve the design of the blade W55RBVS.

Key words: Structural testing, Small wind turbine, Composite blade, Blade testing

\section{INTRODUCTION}

Over the last 25 years, wind turbines have evolved and are now cost competitive with traditional energy sources in many locations. The size of the largest commercial wind turbines, as illustrated in Figure 1, has increased from approximately $50 \mathrm{~kW}$ to $2 \mathrm{MW}$, with machines up to $5 \mathrm{MW}$ under design [09].

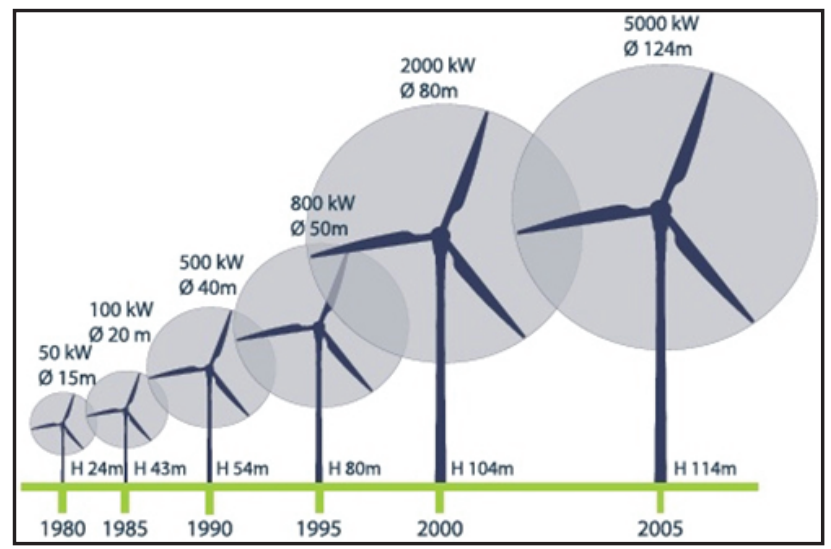

Figure 1: Representative size, height, and diameter of wind turbines
Wind turbine technology, dormant for many years, awoke at the end of $20^{\text {th }}$ century to a world of new opportunities. Developments in many other areas of technology were adapted to wind turbines and have helped to hasten their re-emergence. A few of many areas which have contributed to the new generation of wind turbines include materials science, computer science, aerodynamics, analytical methods, testing, and power electronics. The total installed capacity in the world as of year 2005, as shown in Figure 2 [09], was approximately 60,000 MW, with majority of installations in Europe. Offshore wind energy systems are also under active development in Europe. Design standards and machine certification procedures have been established, so that the reliability and performance are far superior to those of 1970s and 1980s. The cost of energy from wind has dropped to the point that in some sites it is competitive with conventional sources, even without incentives. In those countries where incentives are in place, the rate of development is strong [09]. 


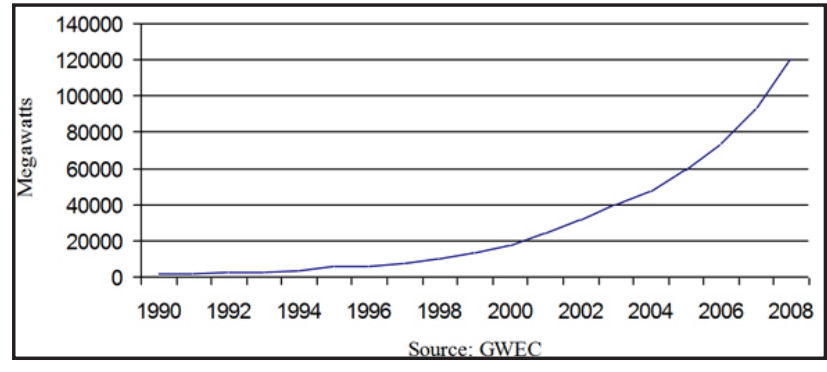

Figure 2: World cumulative installed power capacity, 1990-2008

Like the 1.5 MW turbine shown in Figure 3 [09], most turbines have a horizontally mounted hub with two or three blades. As the blades become longer to capture more power, the static and dynamic loads on the blades and other components increase. In general, a blade for a 1.5-MW turbine is 34 meters in length or greater and weighs as much as $6,000 \mathrm{Kg}(13,200 \mathrm{lbs})$ [05].

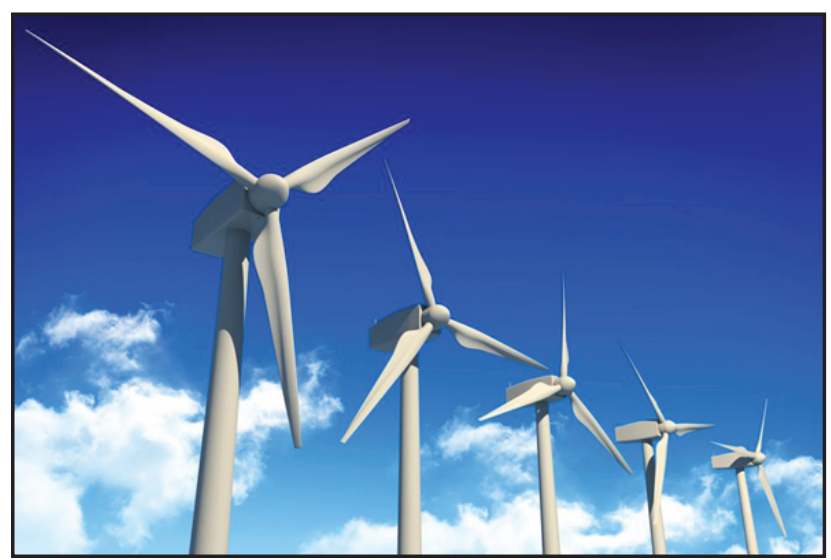

Figure 3: Typical wind turbines

\section{PURPOSE AND IMPORTANCE OF BLADE TESTING}

Because the blades are among the most critical components of the wind turbine, they have to be tested in order to ensure that their specifications are consistent with the actual performance of the blade. According to the International Electrotechnical Commission (IEC) report, TS 61400 pt 23, the fundamental purpose of a wind turbine blade test is to demonstrate to a reasonable level of certainty that a blade type, when manufactured according to a certain set of specifications, has the prescribed reliability with reference to specific limit states, or, more precisely, to verify that the specified limit states are not reached and the blades therefore possess the strength and service life provided for in the design [05]. It must be demonstrated that the blade can withstand both the ultimate loads and the fatigue loads to which the blade is expected to be subjected during its designed service life. In other words, the blade should not fail before the end of its expected service life. Testing of the blades statically and dynamically helps in improving the designs and the manufacturing processes, which further helps in progress of the wind industry as a whole. In field, the blades are typically subjected to normal operating conditions only. Such testing does not ensure that the blade can withstand extreme operating conditions.

\section{BLADE W55RBVS}

The purpose of this research is to test the established technology of designing the composite rotor blade W55RBVS of wind turbine Scirocco. Scirocco is a $5.6 \mathrm{~m}$ diameter rotor, $6 \mathrm{~kW}$ output professional-scale wind turbine ideal for remote sites with medium power needs, such as small farms, houses, or large homesteads and especially rural or village electrification, sea water desalination, direct electrical water run-of-the-wind pumping. This wind turbine is common practice and built in several countries in Europe and America (Figures 4 and 6) [05].
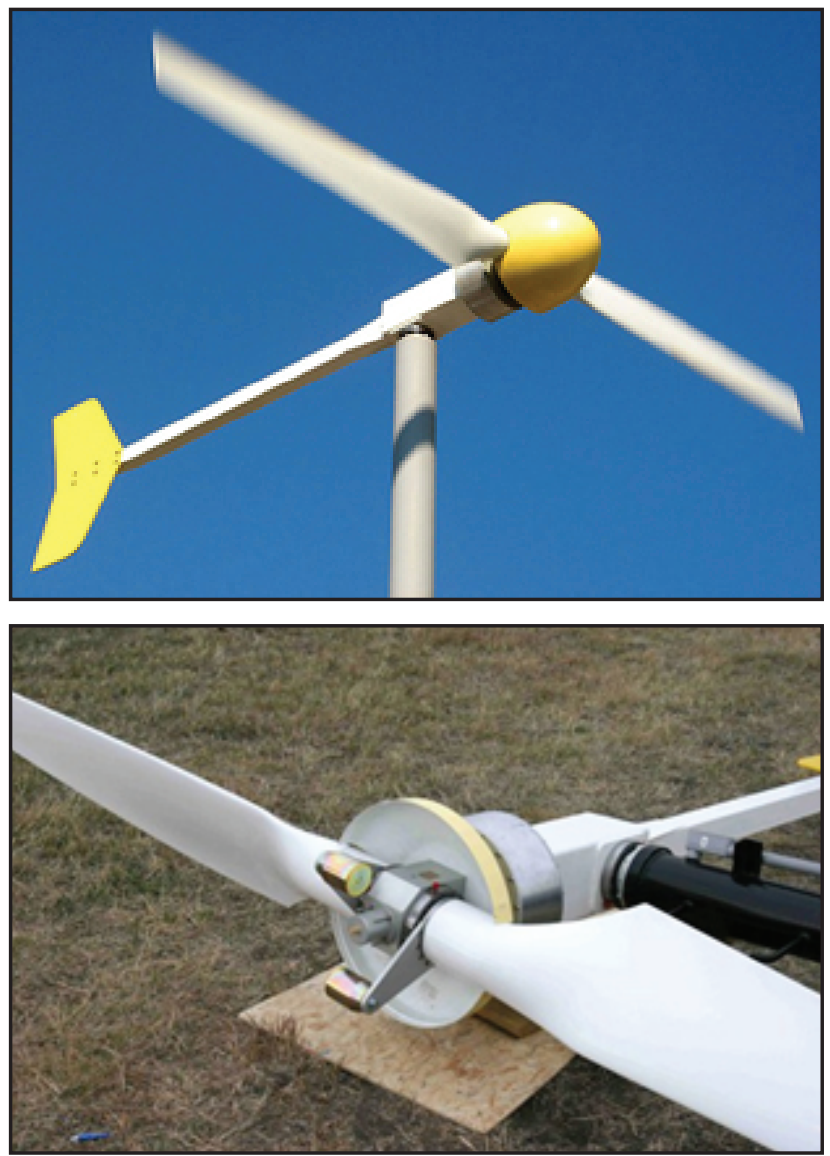

Figure 4: Wind turbine Eoltec Scirocco 
Unlike most of its competitors, which use furling technique to decrease acquisition cost at the detriment of performances and reliability, Scirocco WT is designed and realized without compromise, using state of the art components, centrif- ugal pitch overspeed regulation device, slewing rings for blades attachment and yawing, 100\% sealed direct drive permanent magnet generator. Design and calculations have been made according with IEC 61400-2 design rules [06].

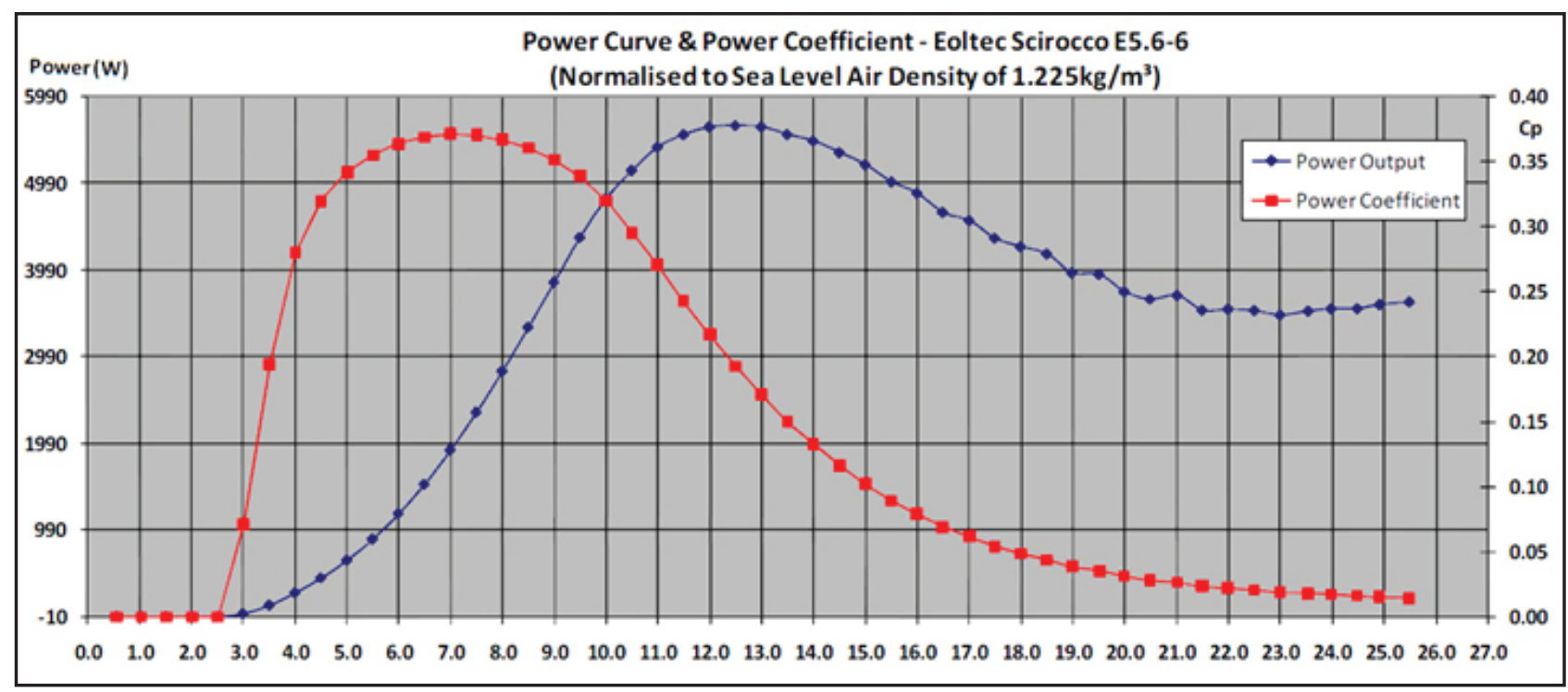

Figure 5: Power Curve \& Power Coefficient at Sea Level Air Density of 1.225 [kg/m $\mathrm{m}^{3}$ [06]

Scirocco is characterized by low rotation speed, a very high efficiency, more particularly in the lower to medium wind speed range which is prevailing most of the time. This is the result of the conjunction of an optimized 2 blades rotor, an efficient direct drive PM generator, and variable speed management combined with the maximal power point tracking control following the constantly varying wind speed. Composite rotor blades W55RBVS are produced in the WING. d.o.o company (Figure 7) [01].

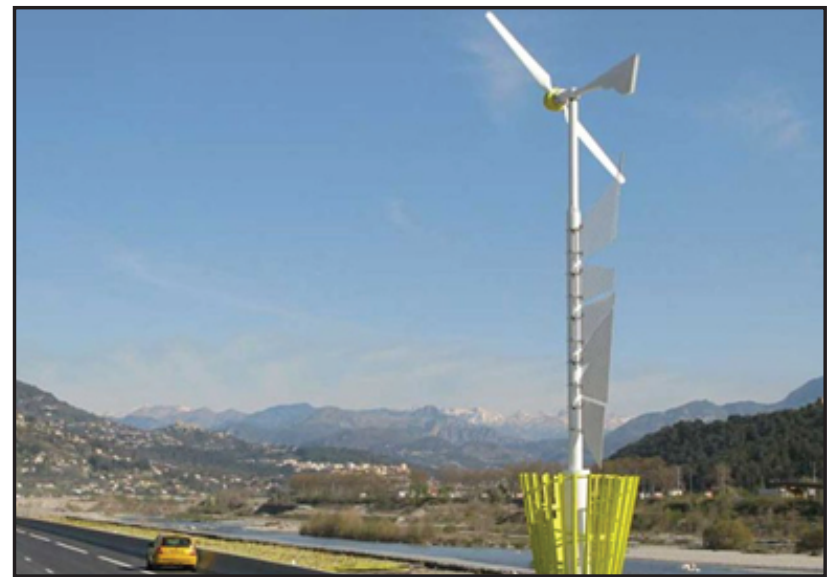

Figure 6: Eoltec Scirocco wind turbine along the highway in France

The design of rotor blades is balanced integration of aerodynamic, structural analysis and dynam- ics, choice of different type of composite materials, production technology and overall economy. The design of modern rotor includes choice of blade number, airfoil, chord and twist distribution. Additional criteria are reliability, noise and aesthetic considerations. The blade design process is multi-objective and generally include two optimization functions, maximum annual energy production or minimum cost of energy. To optimize minimum cost of energy requires a multi-disciplinary method that includes an aerodynamic model, structural model, along with cost models for the blades and all major wind turbine components.

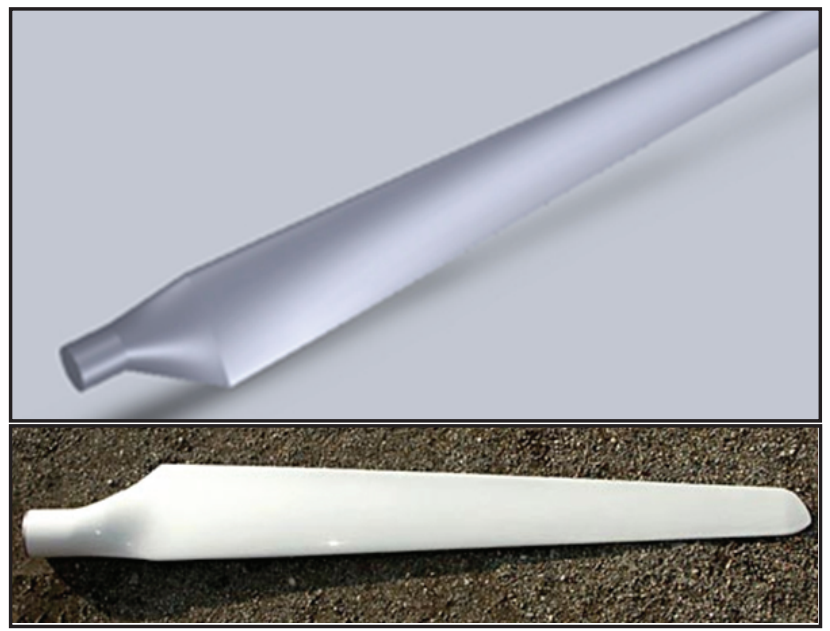

Figure 7: Design of composite blades W55RBVS 


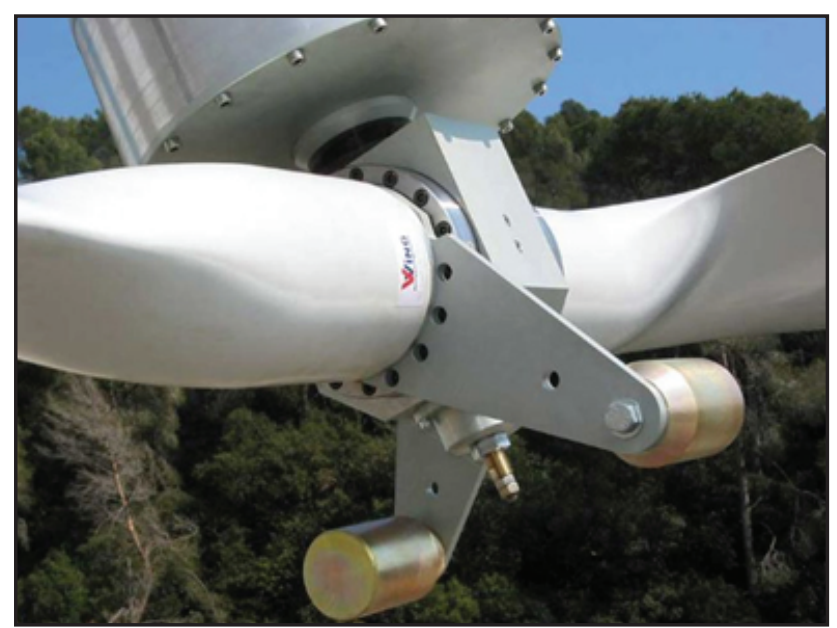

Figure 8: Built-composite blades W55RBVS

\section{BLADE TESTING METHODS}

Generally, the blade testing methods fall into two main categories, static testing and fatigue testing of the blade. The test load can either be loadbased or strength-based. [01], [02], [03], [08].

The purpose of the load-based test is to show that the blade will sustain the intended loads without failure, and is normally used as part of a certification process. This type of testing is performed to demonstrate that the tested blade, within a certain level of confidence, has met the structural design requirements with respect to its normal operating or extreme load conditions. Strength based testing uses as-manufactured blade strength data as its basis and blades are tested to failure. This allows a direct verification of the blade strength, and an assessment of ways in which the design computations, and the resulting design itself, might be improved. This method can be used to find the lowest strength location, relative to expected strength, within a broad region.

\section{STATIC TESTING}

In static testing, loads are applied to the blade statically in one direction to establish its ultimate strength. This type of test can either be intentionally destructive or non-destructive. This type of testing is done with the purpose of predicting a blade's ability to withstand extreme loads such as those caused by hurricane wind forces or unusual transient conditions, in order to determine the ultimate strength of the blade. Static testing is accomplished in a number of ways. The most common of these uses electric winch system, due to ease of controlling it.

\section{PROGRAME FOR TESTING}

The programme for testing rigidity of the composite rotor blade W55RBVS, made in WING.d.o.o. company, of the wind turbine Scirocco is defined by standard IEC 61400-2. The rotor blade testing is done in aerotechnique laboratory at the Faculty of Mechanical Engineering, Belgrade University [03], [04]. The purpose of this testing is to define rigidity of the rotor blade and to determine the maximum force that causes the failure of the rotor blade as well as the spot of the failure.

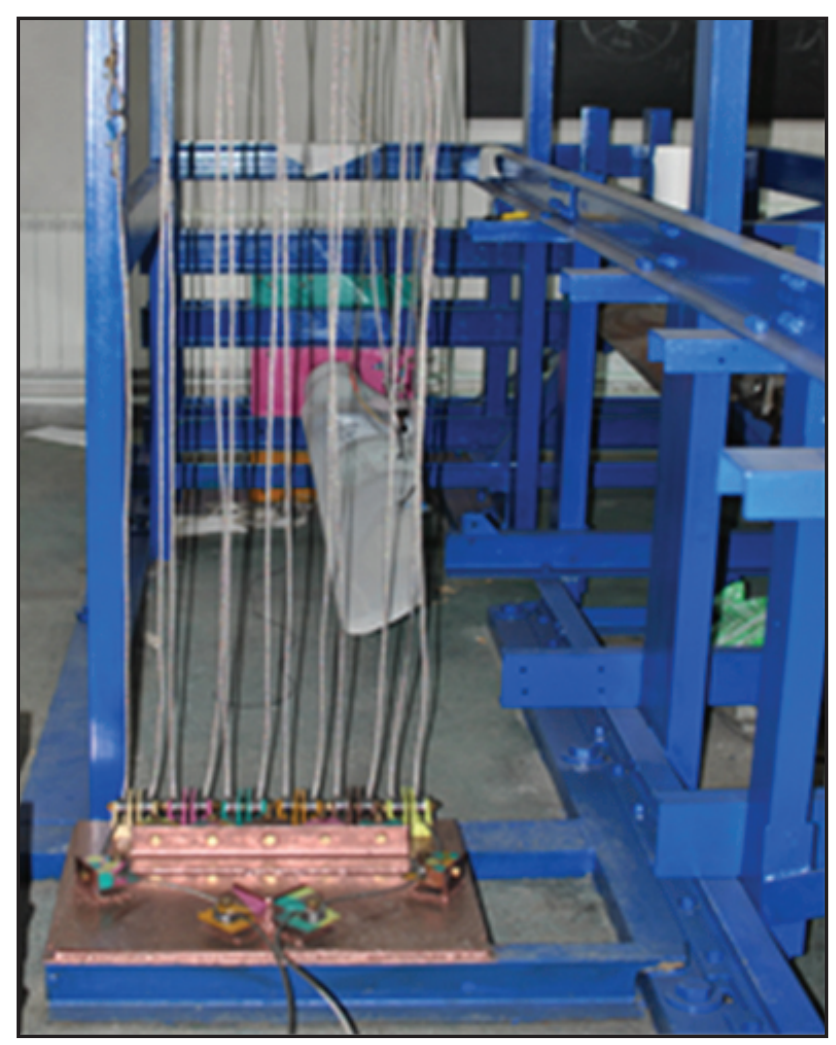

Figure 9: Static sistem for force distribution

Methods used for this purpose and the way of performing this testing are common practice of aeronautical reseach institutes.

\section{ROTOR BLADE ACCEPTANCE}

Rotor blade acceptance provides a holding link between the wind turbine blade and the test table grid. The rotor blade is mounted on the structure at the angle of attack.

A special rotor blade holder that constitutes of extremely rigid specious grid made of steel $C$ and $L$ profiles that are mutually connected by bolt links is prepared for this testing. The link between the rotor blade and the holder is accomplished through $30 \mathrm{~mm}$ board and by bolts M8 of 8.8 quality. 


\section{MEASURING EQUIPMENT}

The central acquisition unit HBM SPIDER 8 represents a multifunctional model of receiving analogue and digital signals with parallel tracing the flow of input units, by means of integrated microcomputer, using higher level system to relieve the acquisition route and providing the flow of signals from certain "smart sensors" directly to the control unit.

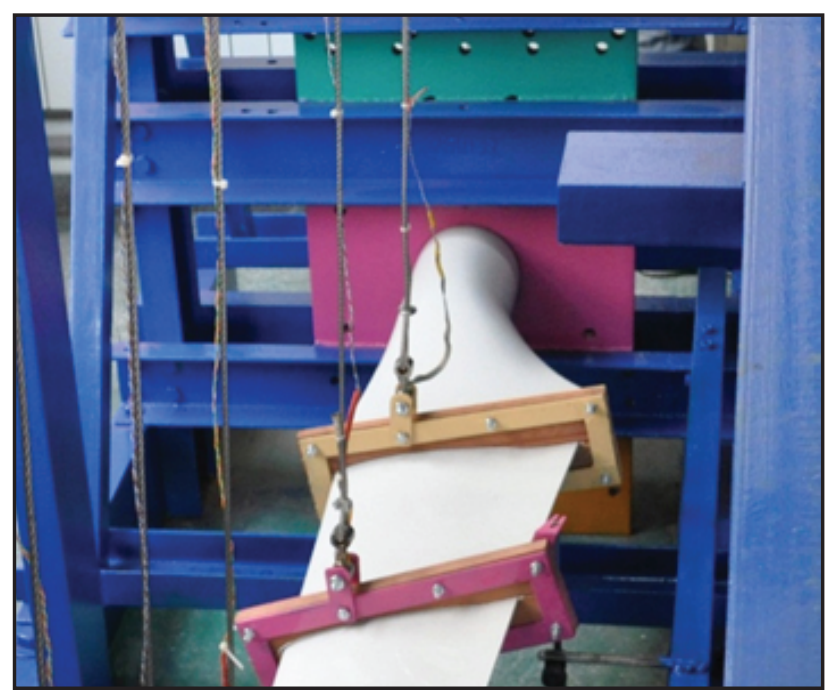

Figure 10: Rotor blade acceptance

SPIDER 8 is a multichannel acquisition unit designed for dynamic parallel measuring. Thanks to integration with personal computer as a higher level system, the process of measuring is remarkably simple and the total acquisition system is compact and of small dimensions. This eight-channel acquisition unit provides 9600 measurings per second per each channel with resolution of 16 bits. All 8 A/D convertors work simultaneously and in a real time follow the transformation of physical values into a digital signal.

Two modules are used for this experiment in this way providing that 16 measuring values are at a disposal for the experiment. Measuring of chosen spot movement on the wind turbine blade is performed by means of standard inductive movement measurer LVDT brand HBM accuracy class $\pm 0,2 \%$ and measuring scale from \pm 1 to $\pm 500 \mathrm{~mm}$. Measuring is performed considering four different spots.

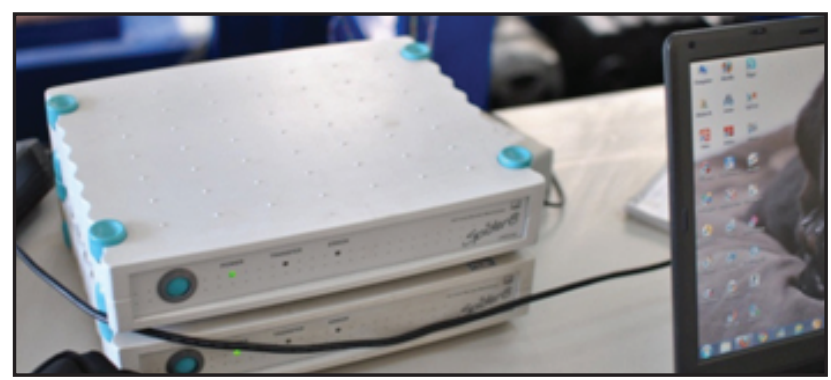

Figure 11: Two modules of SPIDER 8

Journal of Applied Engineering Science 12(2014)2, 285

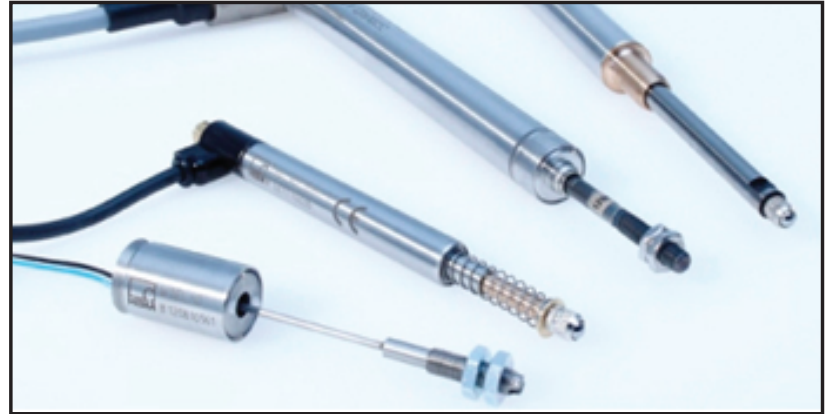

Figure 12: Inductive displacement sensor LVDT- HBM

Six force sensors specially made for this purpose are used for measuring the force. Each force sensor consists of four measuring tapes glued on the body of the sensor in a way shown on the Figure 8. The function of the two measuring tapes glued in axial direction is to measure the deformation of the sensor body during its load, while the function of the other two measuring tapes glued crosswise is to compensate the deformations caused by sensor body bending and in this way to provide that the measuring value should be proportional only to axial load.
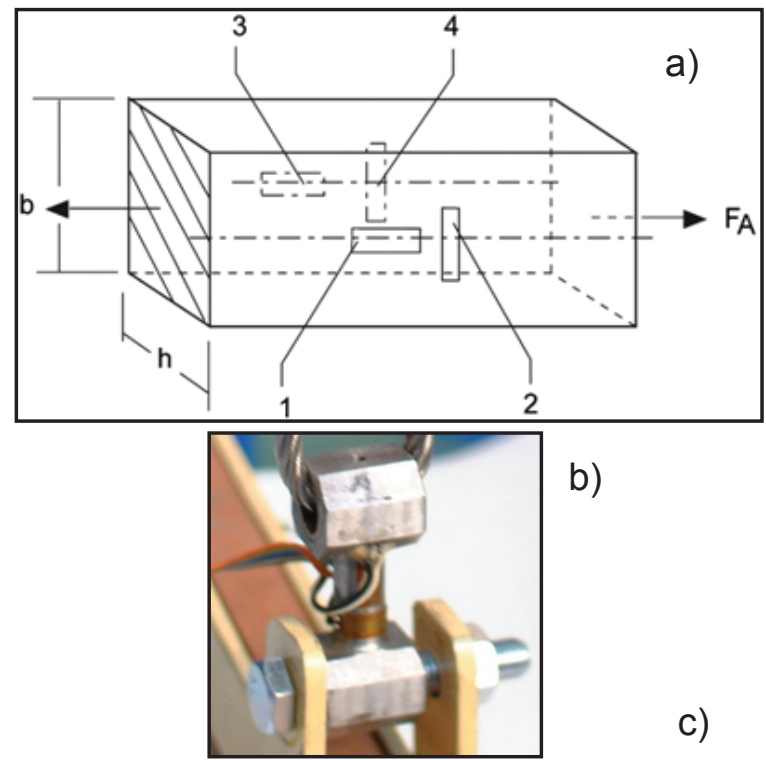

b)

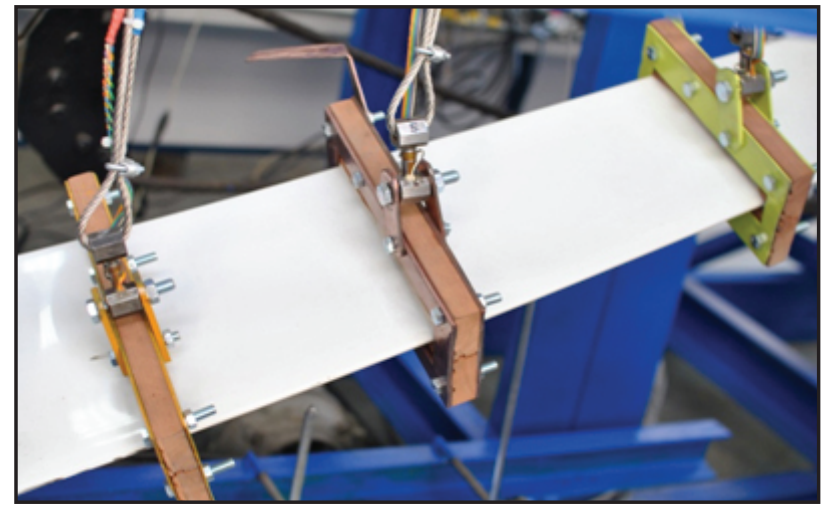

Figure 13: Force sensor a) scheme; b) on the blade c) positioning on the blade 
Each of the force sensors is connected to Vitston full measuring bridge. The measuring bridge is supplied with direct input voltage $\mathrm{VI}$, while output voltage $\mathrm{VO}$ depends on resistance change of the measuring tapes R1, R2, R3 and R4 caused by their deformations and it is proportional to axial force value that influences the sensor. The method of bonding the measuring tapes into measuring bridge provides above mentioned compensation of bending moment influences on the output voltage. Introducing force is performed by means of specially made system that consists of supporting structure, pulley, reductor unit and engine with frequent control. The maximum force possible that can be achieved with this system is 2500 daN.

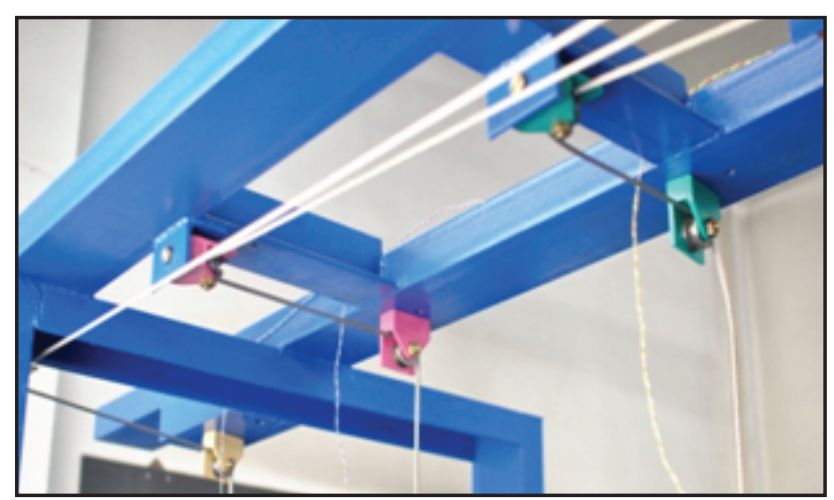

Figure14: Construction for force distribution

\section{REALIZATION OF THE EXPERIMENT}

The rotor blade is loaded in six sections by lyras and measured from the place of the blade clamp. The rotor blade mass is $11.9 \mathrm{~kg}$.

Table 1: Distance from the place of blade clamp

\begin{tabular}{|c|c|c|c|c|c|c|}
\hline Section & 1 & 2 & 3 & 4 & 5 & 6 \\
\hline $\begin{array}{c}\text { Distance } \\
(\mathrm{mm})\end{array}$ & 60.0 & 102.5 & 154.0 & 182.5 & 206.0 & 236.5 \\
\hline
\end{tabular}

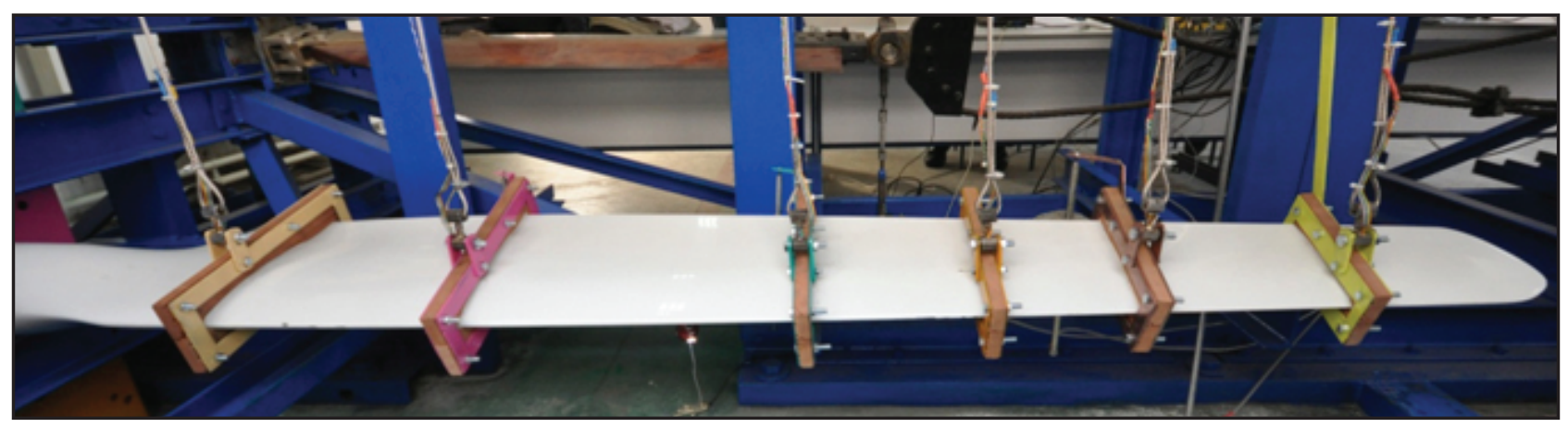

Figure 15: Lyres for the introduction force

The experiment is performed in the accordance with IEC 61400-2 standard. The rotor blade failure is marked with the resulting force of 490.76
daN under maximum deflection of $27.999 \mathrm{~mm}$. After the testing is completed, some separations are recorded on the following distances $(\mathrm{mm})$ :

\begin{tabular}{|l|c|c|c|c|c|}
\hline \multirow{2}{*}{ Leading edge } & Beginning & 56.5 & \multirow{2}{*}{ Trailing edge } & Beginning & 57 \\
\cline { 2 - 3 } \cline { 5 - 5 } & End & 106.5 & & End & 103 \\
\hline
\end{tabular}



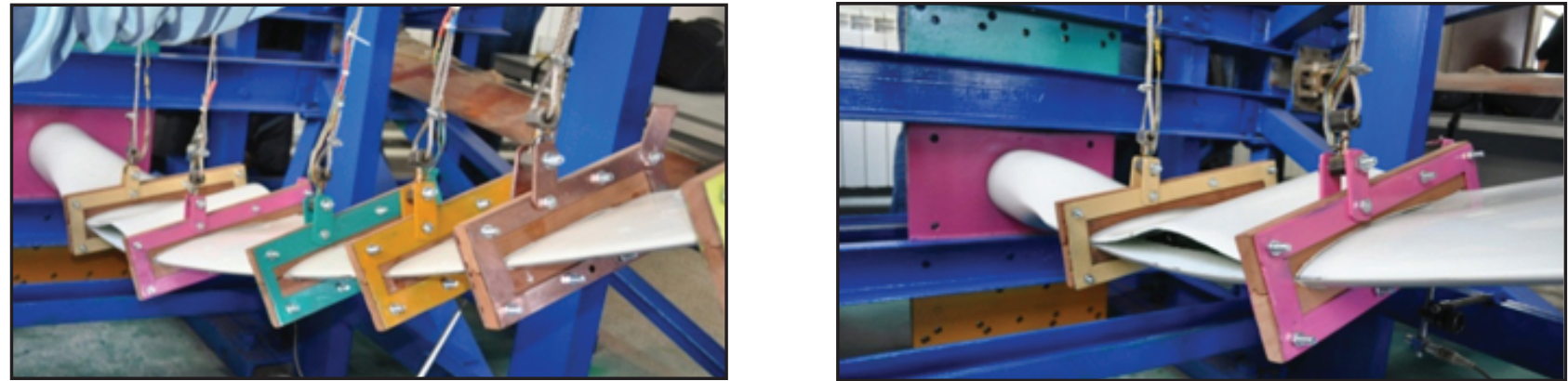

Figure 16: The position of the bladefracture

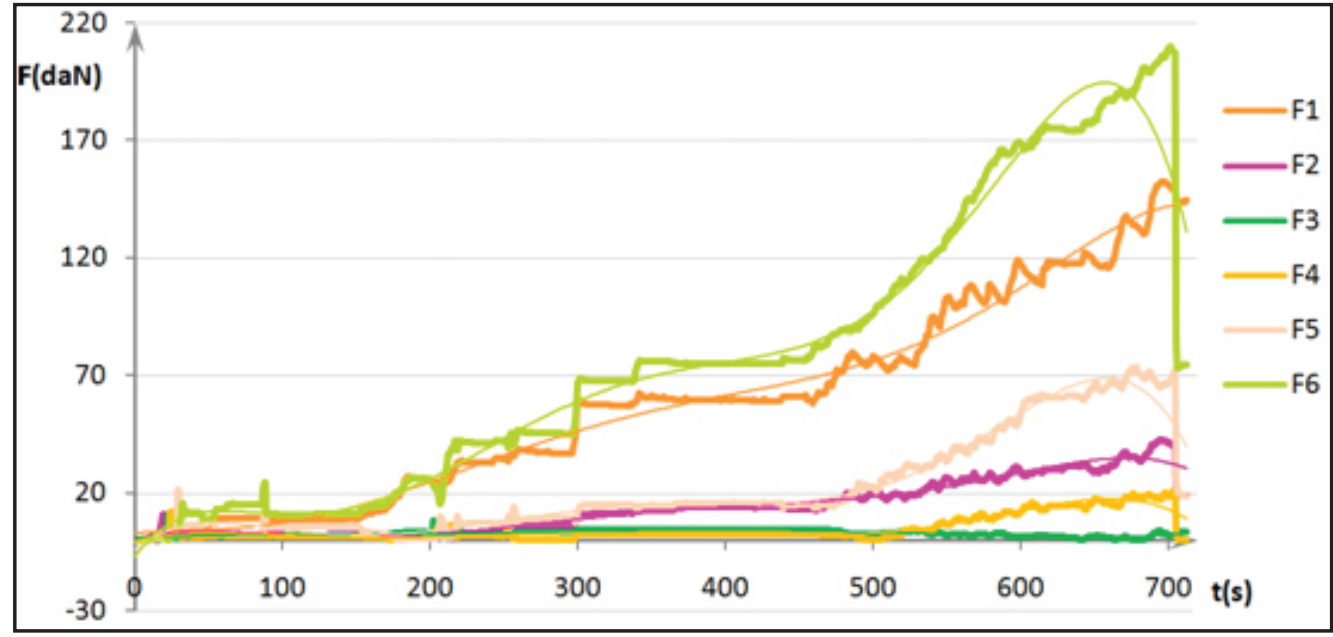

Figure 17:The load distribution of each section in function of time [01]

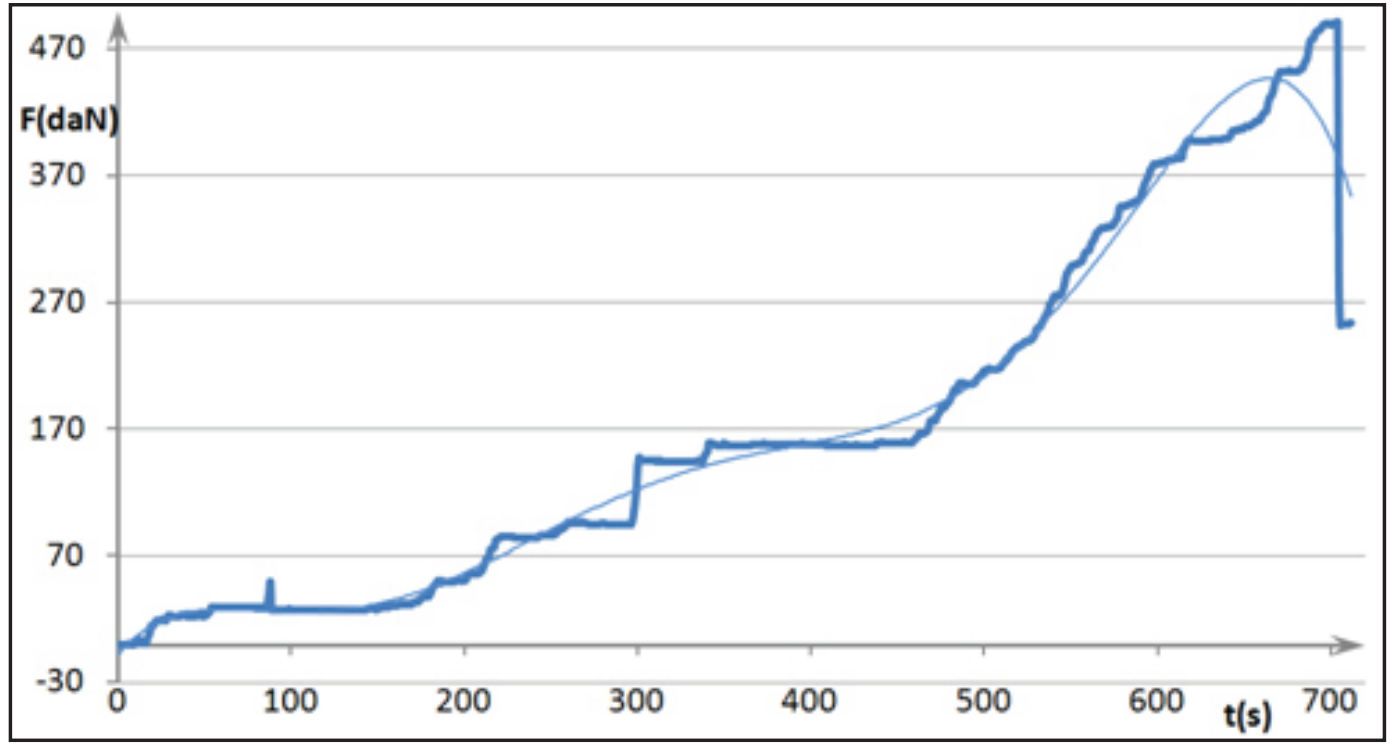

Figure 18: The resulting force distribution in function of time [01]

\section{CONCLUSION}

This experiment confirmed that the wind turbine blade W55RBVS has very high rigidity.

\section{ACKNOWLEDGMENTS}

This research was supported by the Ministry of Science and Technological Development, Republic of Serbia - projects: TR35035, TR36001. 


\section{REFERENCES}

1) C. Mitrovic, N. Petrovic, D. Bekric, A. Bengin, B.Rakicevic "Micro-Structure Characterization of Composite Wind Turbine Blade Following Structural Testing ", Wulfenia Journal, Vol 21, No. 2; Feb 2014, ISSN: 1561-882X

2) C. Mitrovic, N. Petrovic, D. Bekric, V.Dragovic, I.Mileusnic, "Characterization of Micro-structures of Composite of Small Wind Turbine Blade following Structural Testing up to Failure ", The 4th International Conference Advanced Composite Materials Engineering COMAT 2012, 18- 20 October 2012, Brasov, Romania.

3) C. Mitrovic, N. Petrovic, A. Bengin, D. Bekric, V.Dragovic, A.Simonovic, G. Vorotovic, S. Radojevic, D. Stamenkovic, "Structural Testing of Small Wind Turbine Blade up to Failure", International Conference on Innovative Technologies. Conference IN-TECH 2011, Bratislava, 2011.

4) C. Mitrovic, N. Petrovic, D. Bekric, A. Bengin, B.Rakicevic : Micro-Structure Characterization of Composite Wind Turbine Blade Following Structural Testing, International Journal of Engineering \& Technology IJET-IJENS Vol:13 No:01

5) International standard IEC 61400-1, Wind turbines - Part 1: Design requirements, Switzerland.
6) International standard IEC 61400-2, Wind turbines - Part 2: Design requirements for small wind turbines, Switzerland.

7) N.Yahya, M.Kashif, H.Daud, H.Mohd Zaid, A.Shafie, N.Nasir, A.See,:Fabrication and Characterization of Y3.0-XLaXFe5012 PVA Composite as EM Waves Detector, International Journal of Basic \& Applied Sciences IJBAS - IJENS Vol: 9 No: 9, pages 131-134, 2009

8) Pantelis, B., Konstantinidis, E., Pitsa, D. (2012): „Systemic assessment and analysis of factors affect the reliability of a wind turbine", Journal of Applied Engineering Science (Istraživanja i projektovanja za privredu), No. 2, Vol. 10, pp. 85-92

9) Puneet Malhotra "Advanced Blade Testing Methods for Wind Turbines", University of Massachusetts - Amherst, Masters Theses. Paper 529, 2010

10) R.Backers, Eoltec Shirocco E5.6-6, Instalation\&Maintanence Manual, 200920010, Solacity Inc.

Paper sent to revision: 27.03.2014.

Paper ready for publication: 09.06.2014. 